Abstracta Iranica Abstracta Iranica

Revue bibliographique pour le domaine irano-aryen

Volume 42-43 | 2021

Comptes rendus des publications de 2019-2020

\title{
Florence Jullien. « Mobilités conquérantes et nouveaux échanges transfrontaliers. Le moine voyageur en milieu syriaque »
}

Marie-Joseph Pierre

\section{(2) OpenEdition \\ Journals}

Édition électronique

URL : https://journals.openedition.org/abstractairanica/51930

DOI : 10.4000/abstractairanica. 51930

ISSN : 1961-960X

Éditeur :

CNRS (UMR 7528 Mondes iraniens et indiens), Éditions de l'IFRI

Référence électronique

Marie-Joseph Pierre, «Florence Jullien. « Mobilités conquérantes et nouveaux échanges transfrontaliers. Le moine voyageur en milieu syriaque » ", Abstracta Iranica [En ligne], Volume 42-43 2021, document 1, mis en ligne le 30 décembre 2020, consulté le 24 décembre 2022. URL : http:// journals.openedition.org/abstractairanica/51930; DOI : https://doi.org/10.4000/abstractairanica. 51930

Ce document a été généré automatiquement le 24 décembre 2022.

Tous droits réservés 


\title{
Florence Jullien. « Mobilités conquérantes et nouveaux échanges transfrontaliers. Le moine voyageur en milieu syriaque »
}

\author{
Marie-Joseph Pierre
}

\section{RÉFÉRENCE}

Florence Jullien. « Mobilités conquérantes et nouveaux échanges transfrontaliers. Le moine voyageur en milieu syriaque » in O. Delouis, M. Mossakowska-Gaubert, A. PetersCustot (eds.). Les mobilités monastiques en Orient et en Occident de l'Antiquité tardive au Moyen Âge (IVe-XVe siècle). (Collection de l'École française de Rome 558), Rome : École française de Rome, 2019, p. 455-472. <https://books.openedition.org/efr/4385>

1 Cette contribution sur le monachisme oriental missionnaire s'insère dans le cadre d'un programme international tripartite intitulé : " Monks around the Mediterranean. Contacts, Exchanges and Influences in East and West from Late Antiquity to the Middle Ages (4th-15th c.) » initié par Olivier Delouis ("Orient \& Méditerranée", CNRS UMR 8167, Paris), Maria Mossakowska-Gaubert (IFAO, Le Caire) et Annick Peters-Custot (Université de Nantes) entre les années 2012 et 2016. Ce programme a déployé sur quatre ans un cycle de conférences internationales aux thématiques progressives sur les échanges locaux, régionaux puis internationaux des moines autour de la Méditerranée et dans les régions adjacentes durant l'Antiquité tardive et au Moyen Âge (avec des regards comparatifs sur les périodes postérieures). L'ouvrage est le fruit des deux derniers colloques (à Rome, puis à Vienne) consacrés à ces contacts, à une échelle géographique restreinte d'abord, puis sur la longue distance, prenant en compte les mobilités de figures monastiques. 
2 L'A. montre que l'itinérance monastique en milieu syriaque est strictement codifiée dans la littérature canonique et synodale qui fixe un cadre normatif précis pour chaque motif de déplacement. Si le travail en extérieur est très encadré, la documentation témoigne aussi de l'importance des itinérances au niveau régional comme au plus loin, itinérances parfois nécessaires pour la survie d'un courant ecclésial, spécialement le mouvement miaphysite pour lequel le monachisme fut un vecteur essentiel. Les circulations liées à la formation intellectuelle, qui va bien souvent de pair avec la diffusion doctrinale, participent ainsi d'une mobilité conquérante dans le cadre d'une affirmation identitaire d'appartenance christologique. Dans les contextes sociaux et politiques des VIe et VIIe siècles, l'intensification des échanges entre communautés de même obédience devait par ailleurs favoriser une unité supra-frontalière.

\section{AUTEURS}

\section{MARIE-JOSEPH PIERRE}

Directrice d'Études honoraire, EPHE 